\title{
RETRACTED ARTICLE: Real-time voice system in local area network based on cloud computing background and service management of online education colleges
}

\author{
$\mathrm{Ke} \mathrm{Su}{ }^{1} \cdot$ Chae-Kwan Lim $^{2}$
}

Received: 9 June 2021 / Accepted: 28 July 2021 / Published online: 11 August 2021

(C) The Author(s), under exclusive licence to Springer-Verlag London Ltd., part of Springer Nature 2021

The Editor-in-Chief and the Publisher have retracted this article because the content of this article is nonsensical. The peer review process was not carried out in accordance with the Publisher's peer review policy. Author Chae-Kwan Lim has not responded to correspondence regarding this retraction. The Publisher has not been able to obtain a current email address for author $\mathrm{Ke} \mathrm{Su}$. The online version of this article contains the full text of the retracted article as Supplementary Information.

Supplementary Information The online version contains supplementary material available at https://doi.org/10.1007/s00779-021-01612-6.

Chae-Kwan Lim

ys190805@163.com

1 Department of Management, Tongmyong University, Busan 48520, South Korea

2 Department of Distribution Management, Tongmyong University, Busan 48520, South Korea 